\title{
Hyperosmotic stress stimulates autophagy via polycystin-2
}

\author{
Daniel Peña-Oyarzunn ${ }^{1,2, *}$, Rodrigo Troncoso ${ }^{1,3, *}$, Catalina Kretschmar ${ }^{1,4}$, Cecilia \\ Hernando $^{1,4}$, Mauricio Budini ${ }^{4}$, Eugenia Morselli ${ }^{5}$, Sergio Lavandero ${ }^{1,2,6}$ and Alfredo \\ Criollo ${ }^{1,4}$ \\ ${ }^{1}$ Advanced Center for Chronic Diseases, Facultad Ciencias Quimicas y Farmaceuticas \& Facultad Medicina, Universidad de \\ Chile, Santiago, Chile \\ ${ }^{2}$ Center for Molecular Studies of the Cell, Facultad de Medicina, Universidad de Chile, Santiago, Chile \\ ${ }^{3}$ Instituto de Nutrición y Tecnología de los Alimentos, Universidad de Chile, Santiago, Chile \\ ${ }^{4}$ Instituto de Investigación en Ciencias Odontológicas, Facultad de Odontología, Universidad de Chile, Santiago, Chile \\ ${ }^{5}$ Departamento de Fisiología, Facultad de Ciencias Biológicas, Pontificia Universidad Católica de Chile, Santiago, Chile \\ ${ }^{6}$ Department of Internal Medicine (Cardiology Division), University of Texas Southwestern Medical Center, Dallas, TX, USA \\ * These authors have contributed equally to this work \\ Correspondence to: Alfredo Criollo, email: alcriollo@u.uchile.cl
}

Sergio Lavandero, email: slavander@uchile.cl

Keywords: hyperosmotic stress, polycystin-2, mTOR, Autophagy

Received: May 10, $2017 \quad$ Accepted: June 21, 2017

Published: July 05, 2017

Copyright: Oyarzun et al. This is an open-access article distributed under the terms of the Creative Commons Attribution License 3.0 (CC BY 3.0), which permits unrestricted use, distribution, and reproduction in any medium, provided the original author and source are credited.

\section{ABSTRACT}

Various intracellular mechanisms are activated in response to stress, leading to adaptation or death. Autophagy, an intracellular process that promotes lysosomal degradation of proteins, is an adaptive response to several types of stress. Osmotic stress occurs under both physiological and pathological conditions, provoking mechanical stress and activating various osmoadaptive mechanisms. Polycystin-2 (PC2), a membrane protein of the polycystin family, is a mechanical sensor capable of activating the cell signaling pathways required for cell adaptation and survival. Here we show that hyperosmotic stress provoked by treatment with hyperosmolar concentrations of sorbitol or mannitol induces autophagy in HeLa and HCT116 cell lines. In addition, we show that mTOR and AMPK, two stress sensor proteins involved modulating autophagy, are downregulated and upregulated, respectively, when cells are subjected to hyperosmotic stress. Finally, our findings show that PC2 is required to promote hyperosmotic stress-induced autophagy. Downregulation of PC2 prevents inhibition of hyperosmotic stress-induced mTOR pathway activation. In conclusion, our data provide new insight into the role of PC2 as a mechanosensor that modulates autophagy under hyperosmotic stress conditions.

\section{INTRODUCTION}

Osmotic homeostasis is crucial for maintaining normal cell function. Under physiological conditions, renal tubule and gastrointestinal tract cells are routinely subjected to severe changes in osmolarity. However, in other cell types, hyperosmotic stress may promote various human pathologies. For instance, elevated hypertonicity in the extracellular fluid is often associated with ocular tissue disorders involving tear osmolarity and ocular surface inflammation [1, 2], diabetes [3], obesity [4], hypernatremia [5] and inflammatory bowel disease [6, 7]. Imbalanced fluid tonicity provokes osmotic stress, which triggers a series of adaptive mechanisms to ensure cell survival. Transporter translocation [8], transcription factor activation [9], osmolyte synthesis [10], upregulation of antioxidant and chaperone proteins [11], cytoskeletal remodeling [12] and cell volume changes [13] are activated rapidly during osmotic stress. Studies have also reported a correlation between osmotic stress and impaired 
cellular proteostasis [14-16]. Hyperosmotic stress leads to intracellular accumulation of damaged, aggregated, misfolded and oxidized proteins, which can activate cellular degradation mechanisms. Studies have shown that the main cellular protein turnover systems, the autophagy and ubiquitin proteasome pathways, are upregulated under hyperosmotic stress conditions $[17,18]$.

Macroautophagy, hereafter referred to as autophagy, is a catabolic pathway that is highly conserved from yeast to mammals [19]. During autophagy, the cargo, which consists of abnormal and aberrant proteins, proteins with short half-lives and aged or oxidized organelles, is sequestered into double-membrane vesicles known as autophagosomes [20]. Autophagosomes then fuse with the lysosomes to form autophagolysosomes, in which the cargo is degraded by hydrolytic enzymes [20]. Various autophagy-related (ATG) proteins are involved in initiation, nucleation and elongation of autophagosomes $[21,22]$. In general, downregulation of ATG proteins strongly inhibits autophagy. The autophagic mechanism can be fine-tuned by the stress sensor proteins AMPdependent kinase (AMPK) and the mechanistic target of rapamycin (mTOR) [20,23]. Thus, under basal conditions, the constitutive Ser/Thr kinase activity of mTOR [23] represses autophagy. When cells are subjected to stressors such as nutrient deprivation, autophagy may be activated by suppression of mTOR activity or increased Ser/Thr kinase activity of AMPK [23].

Few studies have evaluated the role of hyperosmotic stress in autophagy induction. In yeast, osmolytes such as ammonium sulfate, raffinose and sorbitol are capable of inducing autophagy in a p38 mitogen-activated protein kinase (p38 MAPK)-dependent manner [24]. In rat notochordal cells, hyperosmotic solutions containing $\mathrm{NaCl}$ increase autophagy via AMPK. Similar results have been observed in Chinese hamster ovary $(\mathrm{CHO})$ and porcine renal proximal tubule-like (LLC-PK) cell lines, in which hypertonic solutions of $\mathrm{NaCl}$ induce autophagosome formation [25-27]. Additionally, we have shown in previous studies that sorbitol-induced hyperosmotic stress activates nuclear factor kappa beta (NF- $\mathrm{KB}$ ) in neonatal rat cardiomyocytes [28-30]. This transcription factor modulates the autophagic response in multiple cell types [28-30]. We have also reported that hyperosmolar solutions of sorbitol or mannitol lead to mitochondrial proton gradient dissipation, resulting in mitochondrial dysfunction [31]. This disruption may promote selective degradation of mitochondria by autophagy, a process known as mitophagy [17]. Although autophagy is recognized as an important adaptive response to hyperosmotic stress, few studies have explored autophagy in human cells, and little is known about the mechanotransducers involved in sensing osmotic changes and triggering autophagy.

Importantly, polycystins (PCs) represent a large family of proteins associated with mechanotransduction pathways [32, 33]. One member of this family, polycystin-2 (PC2), has been studied extensively due to its role in human polycystic kidney disease (PKD). PC2 forms a complex with polycystin-1 (PC1) that contributes to mechanosensation, detecting tonicity changes, fluid shear stress and fluid flow in the kidney. Specific PC2 mutations lead to PKD, which is characterized by impaired cell volume regulation leading to formation of kidney cysts [34]. Interestingly, rapamycin, a pharmacological inhibitor of mTOR and consequently a strong inducer of autophagy, attenuates PKD symptoms in patients and animal models by modulating cell size [35-38]. These findings are consistent with results in PC2-deficient cell lines, where correlations between $\mathrm{PC}$ and mTOR pathway activity have been found. PC2 and mTOR are involved in modulating stress-induced autophagy [39]. Collectively, these studies suggest that impaired autophagy may be related to altered PC2 activity [40-43]. Therefore, it is possible that PC2 is required not only for mechanosensation, as has largely been demonstrated, but also for adaptively maintaining proteostasis in cells subjected to osmotic stress.

Here, we show that osmotic stress, induced by treatment with hyperosmotic solutions of sorbitol or mannitol, induces autophagy in the human cell lines HeLa and HCT116. Moreover, we show that hyperosmotic stress induces autophagy by modulating the classic mTOR and AMPK pathways. Finally, we show that PC2 is required for hyperosmotic stress-induced autophagy, produced by modulation of the mTOR pathway.

\section{RESULTS}

\section{Hyperosmotic stress induces autophagy}

To evaluate the effect of hyperosmotic stress on autophagy, two different human cell lines (the human colon tumor cell line HCT116 and the human cervical cancer cell line HeLa) were exposed to various concentrations of sorbitol and mannitol, two osmolytes widely used to increase tonicity in cells [10]. Both compounds induced autophagy at different concentrations, reaching the highest levels at $200 \mathrm{mOsm}$, as assessed by quantification of autophagic vacuoles with fluorescence microscopy (Figures 1A-1C) and quantification of LC3 I-to-LC3 II conversion by Western blot analysis (Figures $1 \mathrm{D}, 1 \mathrm{E})$. Time-dependent changes in autophagy were also assessed in HeLa and HCT116 cells treated with sorbitol or mannitol. Increased autophagy was observed at $0.5,1$ and $2 \mathrm{~h}$ post-stimulation with sorbitol or mannitol (200 mOsm) (Figures 1F-1H). We also analyzed levels of p62/SQSTM1, an autophagosome cargo protein that is specifically degraded when autophagy is upregulated [44]. p62/SQSTM1 was degraded when cells were treated with sorbitol or mannitol at 200 or $300 \mathrm{mOsm}$ (Figure 1D) for 2, 
A
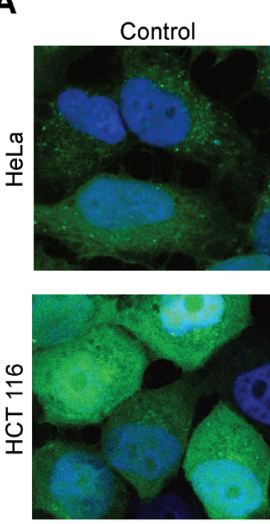

GFP-LC3/Hoechst

D

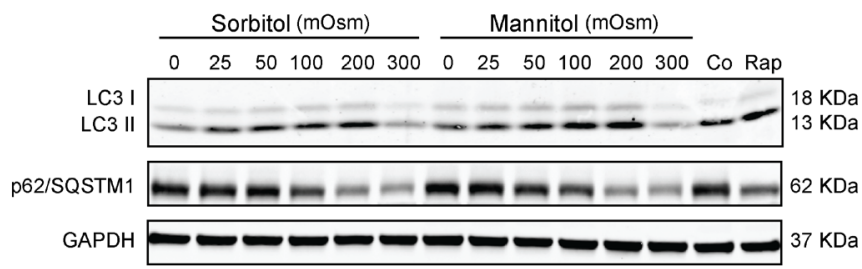

$\mathbf{F}$

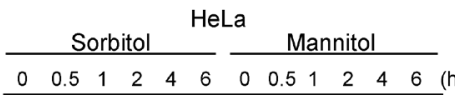

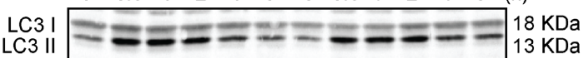
p62/SQSTM1 $-2-w 62 \mathrm{KDa}$ $\alpha$-Tubulin

G HCT116 Mannitol

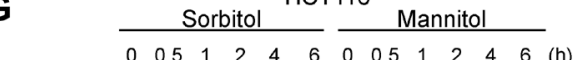
LC3 I $=-\ldots-\ldots-\ldots$ LC3 II - - - - - - $13 \mathrm{KDa}$ p62/SQSTM1 $-----m-m 62 \mathrm{KDa}$ $\alpha$-Tubulin $-20 \mathrm{KDa}$

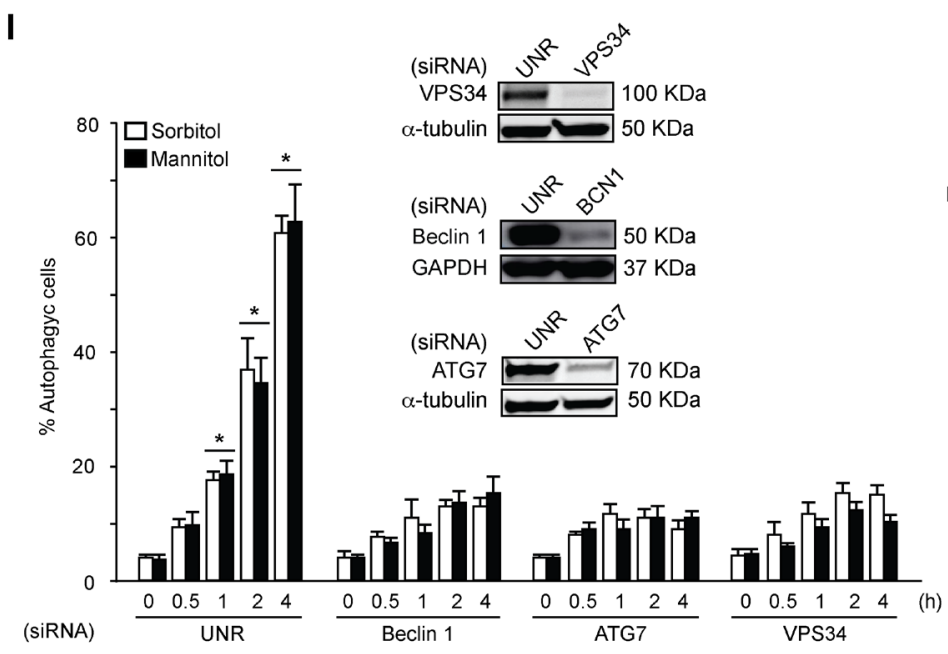

\section{B}

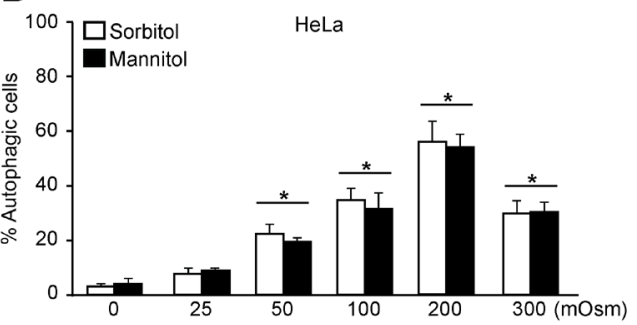

C

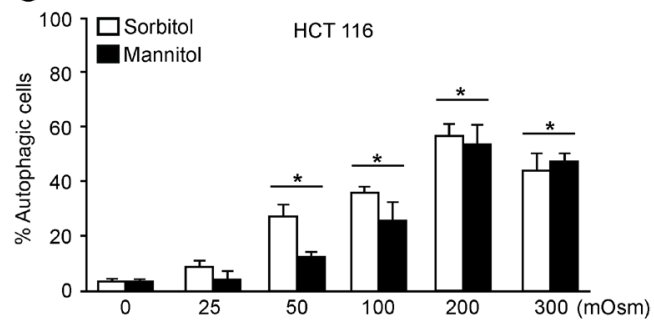

E

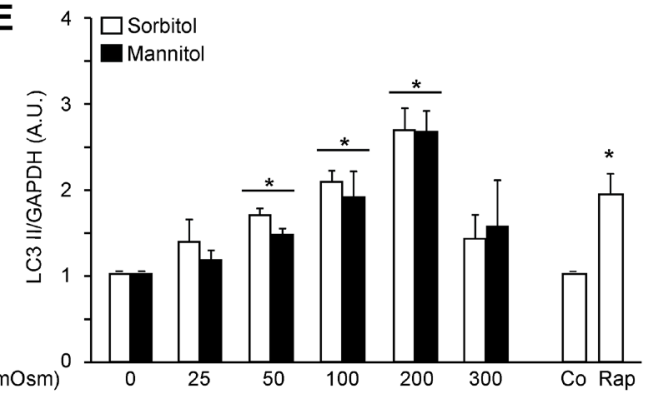

H

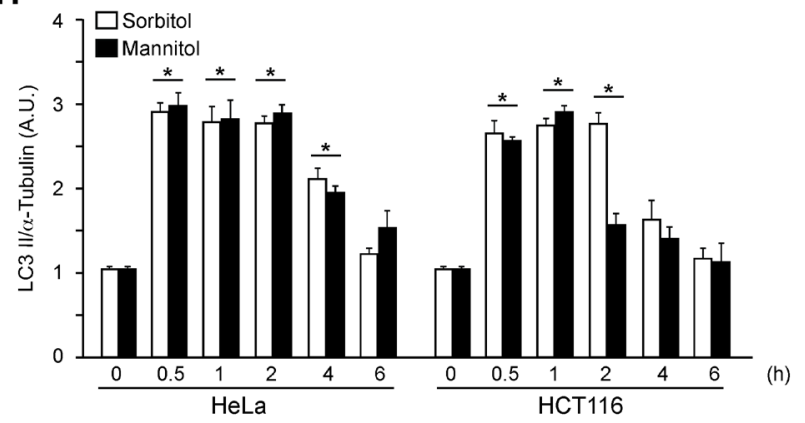

J

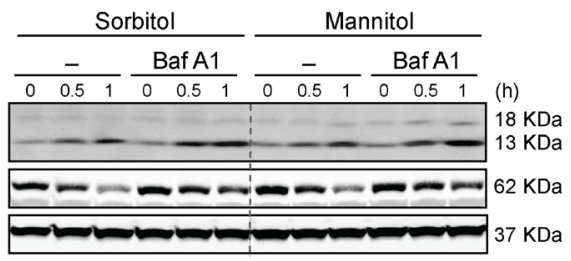

K

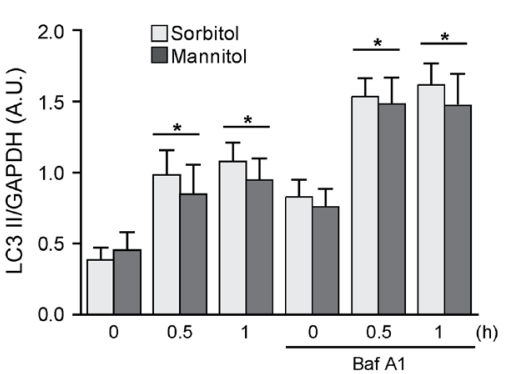


Figure 1: Hyperosmotic stress stimulates autophagy. HeLa and HCT 116 cells were transduced with an adenovirus coding for GFP-LC3 (Ad GFP-LC3) for $24 \mathrm{~h}$. Cultures were then exposed to different concentrations (25-300 mOsm) of sorbitol or mannitol for $2 \mathrm{~h}$. Subsequently, autophagy was evaluated by fluorescent microscopy. $1 \mu \mathrm{M}$ of rapamycin was used as a positive control to induce autophagy. Nuclei were dyed with $10 \mathrm{ng} / \mathrm{mL}$ of DAPI. Representative pictures are shown in A.. The percentage of cells with GFP-LC3 puncta (autophagic cells) in HeLa and HCT116 are shown in B. and C., respectively (mean $\pm \mathrm{SEM}, n=3,{ }^{*} p<0.05 v s .0 \mathrm{mOsm}$ ). LC3 I-to-LC3 II conversion and p62/SQSTM1 depletion were assessed by Western blot analysis in HeLa and HCT116 cells treated with various concentrations of sorbitol or mannitol (25-300 mOsm) D., E. for the indicated times (0.5-6 h) F.-H. Representative gels are shown in D., F. and G.. Quantification of gel bands is shown in E. and H. (mean $\pm \mathrm{SEM}, n=3,{ }^{*} p<0.05$ vs. $0 \mathrm{mOsm}$ or $0 \mathrm{~h}$ ). HeLa cells were transfected with specific siRNAs against Beclin 1, ATG7 or VPS34, followed by infection with Ad GFP-LC3. Subsequently, cells were treated with $200 \mathrm{mOsm}$ of sorbitol or mannitol for $0,0.5,1,2$ or $4 \mathrm{~h}$. Autophagy was evaluated by fluorescent microscopy. The percentage of autophagic cells was quantified, shown in $\mathbf{I} .\left({ }^{*} p<0.05 v s .0 \mathrm{~h}\right)$ and representative gels inserted in the graphic indicate the efficiency of siRNA downregulation for Beclin 1, ATG7 and VPS34 I. An unrelated siRNA (UNR) was used as a control. GAPDH and $\alpha$-tubulin were used as loading controls J.-K. The effect of BafA1 treatment on LC3 I-to-LC3 II conversion and p62/SQSTM1 degradation under hyperosmotic stress conditions was assessed. HeLa cell cultures were exposed to sorbitol or mannitol (200 mOsm) for $0,0.5$ or $1 \mathrm{~h}$ in the presence or absence of $50 \mathrm{nM}$ of BafA1. LC3 II and p62/SQSTM1 levels were then determined by Western blot analysis J.. GAPDH levels were monitored as a loading control. Quantification of gel bands is shown in K. (mean \pm SEM, $n=3, * p<0.05 v s .0$ h).

4 or $6 \mathrm{~h}$ (Figures 1F, 1G), confirming autophagy induction. Importantly, all experiments were also performed with rapamycin as a positive control. Rapamycin is a classic autophagy inducer and, as predicted, stimulated LC3 I-toLC3 II conversion and p62/SQSTM1 degradation in HeLa cells $[45,46]$ (Figures 1D, 1E).

To confirm that hyperosmotic stress induces autophagy, we inhibited the autophagic pathway using siRNAs against classic components of the autophagic machinery, such as Beclin 1, ATG7 and vacuolar protein sorting 34 (VPS34) [47-49]. Beclin 1 and VPS34 are part of the class III phosphatidylinositol 3-kinase complex (PI3KC3), which is implicated in the formation of new autophagosomes. ATG7 is an E1-like activating enzyme involved in the ubiquitin-like systems required for autophagosome elongation [20-22]. Downregulation of Beclin 1, ATG7 and VPS34 blocked autophagosome formation in HeLa cells treated with sorbitol or mannitol (Figure 1I). Taken together, these data suggest that hyperosmotic stress induces autophagy.

Elevated autophagosome levels might be caused by increased formation of new autophagosomes or by decreased autophagosome degradation. To discriminate between these two options, autophagic flux was evaluated. This term refers to the entire dynamic process of autophagy from autophagosome synthesis to degradation within the lysosomes $[44,50]$. We exposed HeLa cells to sorbitol or mannitol (200 mOsm) for 0.5 or $1 \mathrm{~h}$ in the presence or absence of $50 \mathrm{nM}$ of Bafilomycin A1 (BafA1). BafA1 is a classical inhibitor of autophagic flux as it blocks the vacuolar $\mathrm{H}^{+} \mathrm{ATPase}$, preventing autophagosome-lysosome fusion $[44,51]$. The LC3 II and p62/SQSTM1 levels measured by Western blot analysis indicated that treatment with BafA1 enhanced sorbitol- and mannitol-induced autophagy (Figures 1J, K). Collectively, these results indicate that various stimuli that promote hyperosmotic stress also induce autophagic flux in HeLa cells.

\section{Hyperosmotic stress inhibits mTOR while activating the AMPK pathway}

We then evaluated the effect of sorbitol- and mannitol-induced autophagy on kinases that regulate the autophagic pathway. To this end, we determined the phosphorylation status of mTOR, which suppresses autophagy [23]; AMPK, which induces autophagy; and their downstream effectors, eukaryotic translation initiation factor 4E-binding protein 1 (4EBP1) and acetylCoA carboxylase (ACC), respectively [52]. HeLa and HCT116 cells were treated with sorbitol and mannitol (200 mOsm) for 0, 5, 15, 30 or 60 min (Figures 2A-2F). mTOR phosphorylation decreased significantly in both cell types after only $5 \mathrm{~min}$ of treatment with sorbitol or mannitol (Figures 2A-2C). 4EBP1 phosphorylation also decreased significantly after 15 min of treatment (Figures 2A, 2B, 2D). Accordingly, phosphorylation of AMPK and its downstream effector ACC increased significantly (Figures 2A, 2B, 2E, 2F). Importantly, we confirmed that autophagy also increased significantly at the same time points, as measured by the conversion of LC3 I to LC3 II (Figures 2A, 2B). Taken together, these experiments indicate that the classical pathways involved in the control of autophagy are affected by hyperosmotic stress.

\section{PC2 is required for hyperosmotic stress-induced autophagy}

PC2 is a member of the PC protein family, which localizes to membranous compartments such as the cytoplasm, endoplasmic reticulum and primary cilium membranes [53-55]. Studies have demonstrated that PC2 participates in mechanotransduction mechanisms, especially in the kidney cells, which are constantly subjected to fluctuations in osmolarity $[33,53,56]$. Since hyperosmotic stress generates mechanical stress by altering cell volume and cytoplasm membrane tension [57, 58], we evaluated the role of PC2 in hyperosmotic stress- 
induced autophagy. HeLa cells were exposed to sorbitol or mannitol (50 or $200 \mathrm{mOsm}$ ) after transfection with an unrelated siRNA (siUNR) or siRNA against PC2 (siPC2). We assessed autophagy by counting the percentage of cells with autophagic puncta with fluorescence microscopy (Figures 3A, 3B) and by quantifying LC3 I and LC3 II levels by Western blotting (Figures 3C-3E). The data,
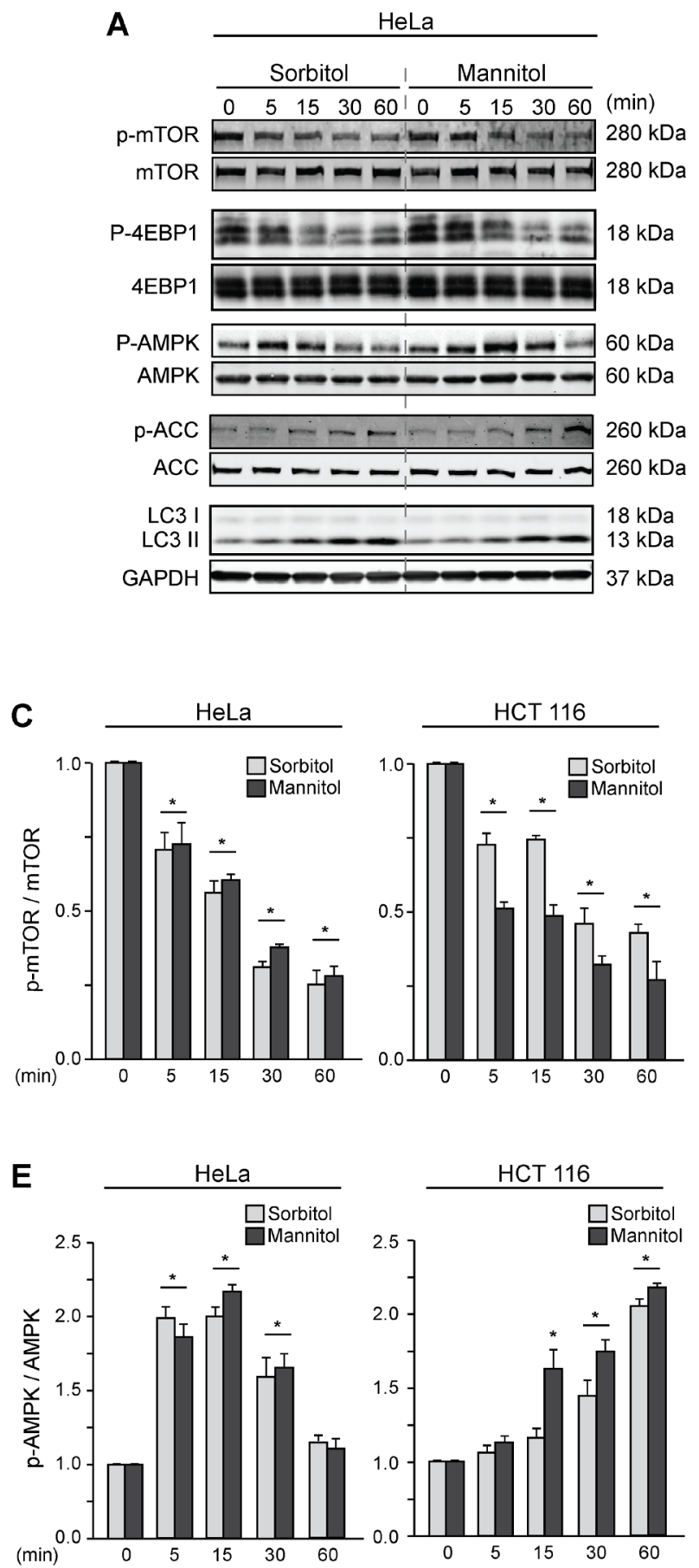

obtained using the two different approaches, show that downregulation of PC2 inhibited hyperosmotic-stress induced autophagy. These results were confirmed in HCT116 cells (Figures 3F, 3G). Given that decreased LC3 I levels are observed under control conditions when PC2 is downregulated, we evaluated the effect of siRNA against PC2 on MAP1LC3B gene expression, using real-
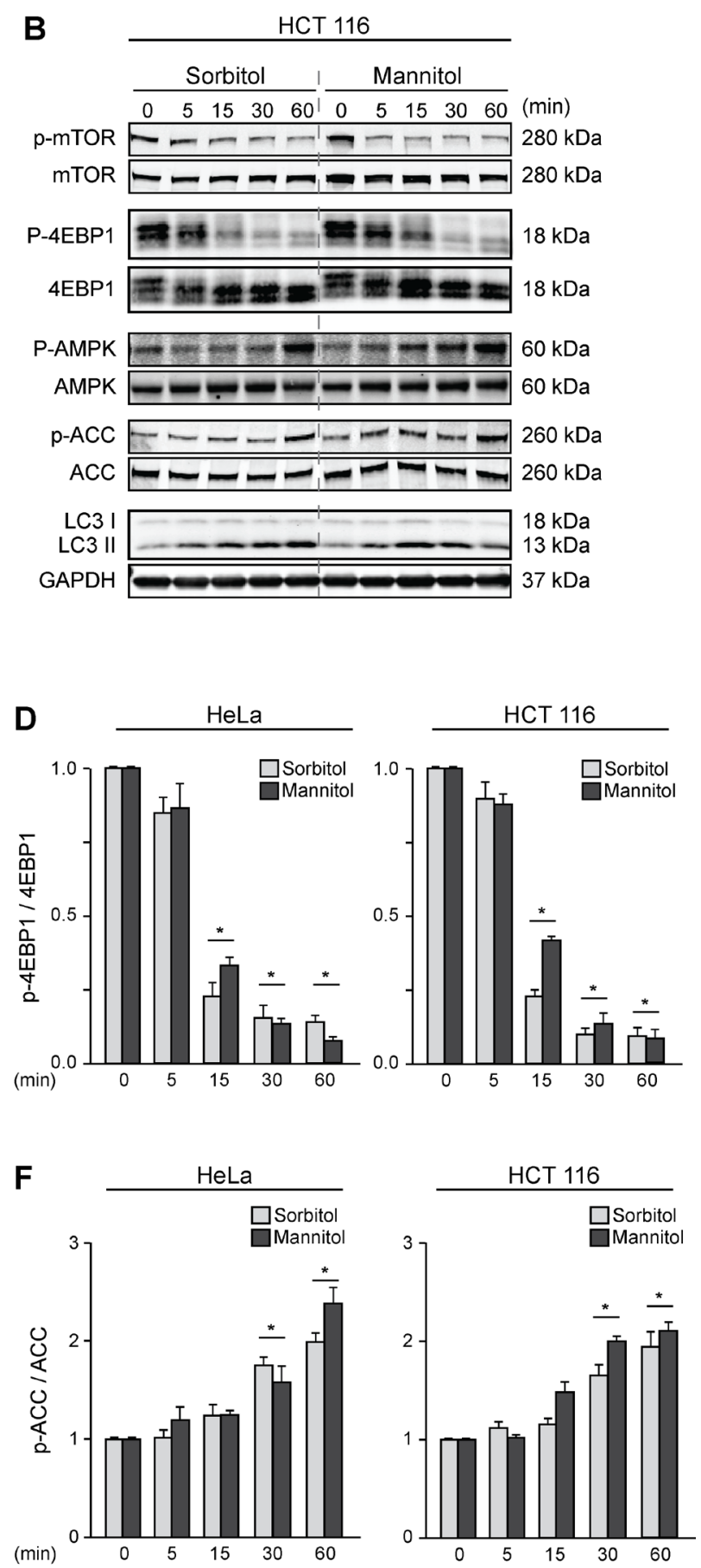

Figure 2: Hyperosmotic stress modulates the mTOR and AMPK pathways. HeLa and HCT116 cultures were exposed to sorbitol or mannitol (200 mOsm) for $0,5,15,30$ or $60 \mathrm{~min}$. Total and phosphorylated forms of mTOR, 4EBP1, AMPK, ACC and LC3 I-toLC3 II conversion were evaluated by Western blot analysis. Representative gels are shown in A. and B.. GAPDH levels were monitored as a loading control. Quantification of gel bands is shown in C.-F. (mean $\pm \mathrm{SEM}, n=3,{ }^{*} p<0.05 v s .0 \mathrm{~min}$ ). 
A

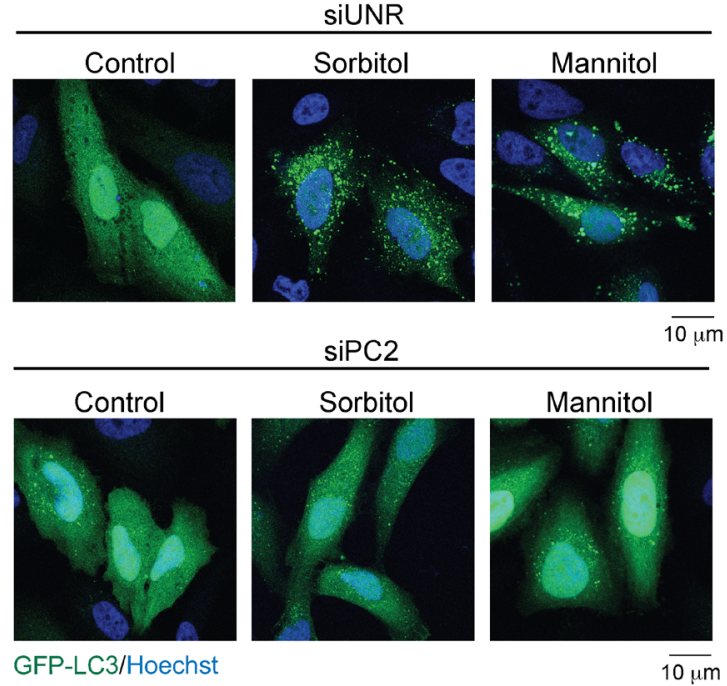

B

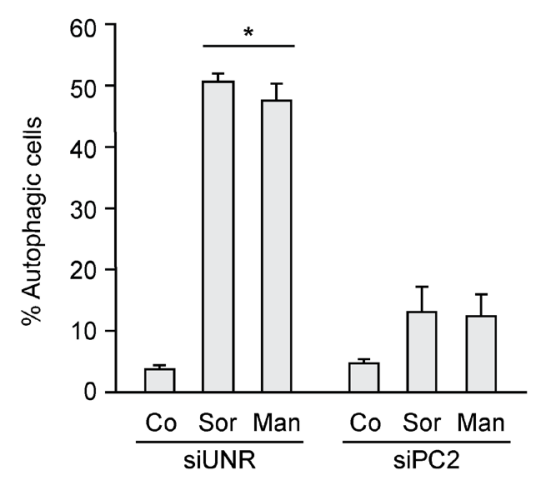

C

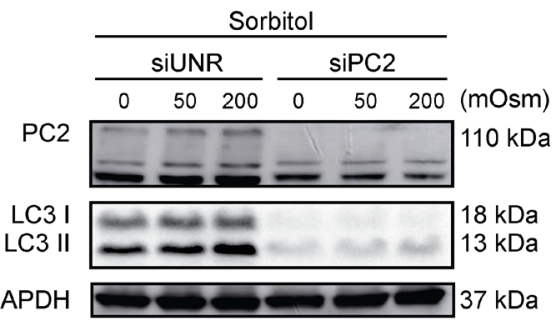

D

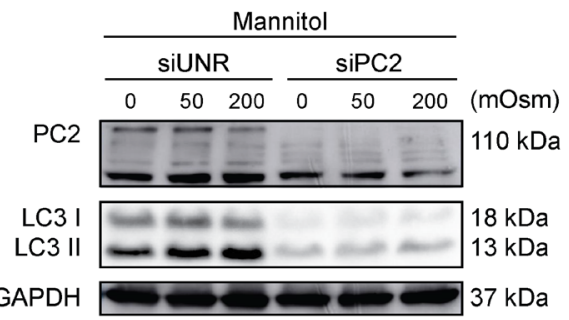

$\mathbf{F}$

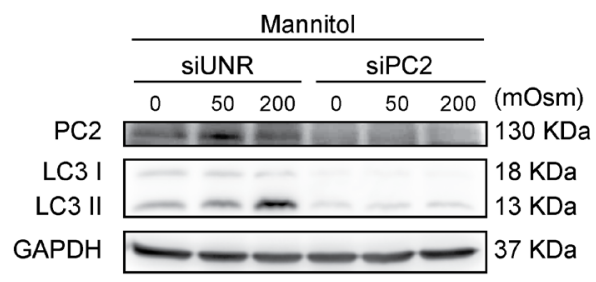

E

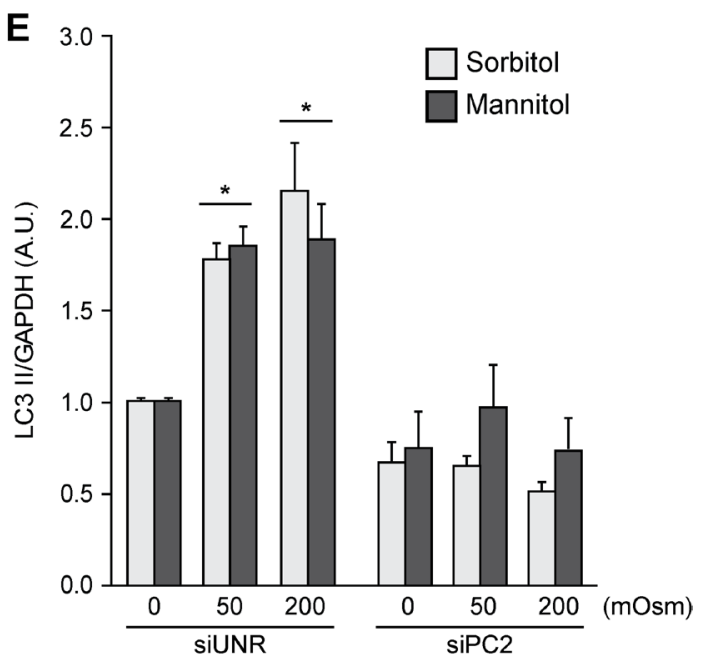

G

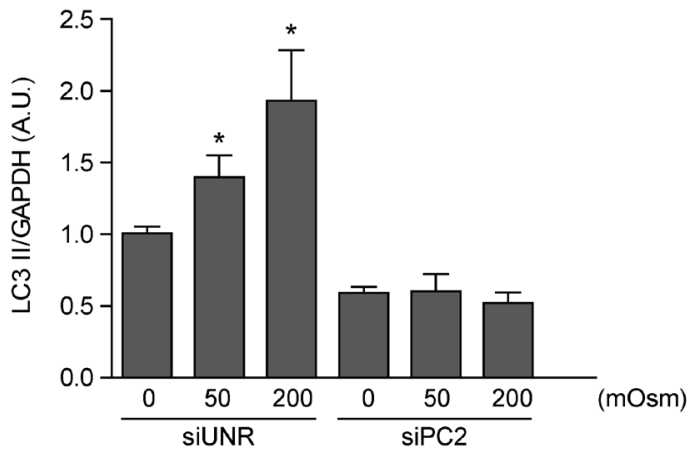

Figure 3: PC2 is required for hyperosmotic stress-induced autophagy. PC2 was downregulated in HeLa cells by a specific siRNA against PC2. An unrelated siRNA (UNR) was used as a control. Subsequently, cells were infected with AdGFP-LC3 for $24 \mathrm{~h}$ and treated with sorbitol or mannitol $(200 \mathrm{mOsm})$ for $2 \mathrm{~h}$. Cells were fixed, and autophagy was evaluated by fluorescence microscopy. Representative pictures are shown in A. The percentage of autophagic cells is shown in B. (mean $\pm \mathrm{SEM}, n=3,{ }^{*} p<0.05 v s$. Co siUNR). Nuclei were dyed with $10 \mathrm{ng} / \mathrm{mL}$ of DAPI C.-G. PC2 was downregulated in HeLa C.-E. and HCT116 F.-G. cells with a specific siRNA against PC2. LC3 I-to-LC3 II conversion was evaluated by Western blot analysis in HeLa C.-E. and HCT116 F.-G. cells exposed to sorbitol or mannitol (0, 50 or $200 \mathrm{mOsm})$ for $2 \mathrm{~h}$. Representative gels are shown in C., D. and F.. Quantification of gel bands is shown in shown in E. and G. (mean \pm SEM, $n=3, * p<0.05$ vs. 0 mOsm siUNR). GAPDH levels were used as a loading control. 
time quantitative reverse transcription (RT-qPCR). Our results showed that $M A P 1 L C 3 B$ expression was unaltered by downregulation of $\mathrm{PC} 2$, indicating that regulation of PC2-mediated autophagy is independent of MAP1LC3B expression (Supplementary Figure S1).

Autophagy is considered to be a pro-survival mechanism that prevents cell death under stress conditions [59]. When autophagy was blocked by downregulation of Beclin 1, an essential autophagic protein [47], exposing HeLa cells to sorbitol enhanced apoptosis, as indicated by elevated short caspase-3 levels (Figures 4A, 4B). Interestingly, similar findings were observed when PC2 was downregulated. These data were also consistent with the results for mitochondrial transmembrane potential $\left(\Delta \Psi_{\mathrm{m}}\right)$, evaluated by cytometry with the $\Delta \Psi_{\mathrm{m}}$-sensitive dye $\operatorname{DiOC}_{6}(3)$. Given that dissipation of $\Delta \Psi_{\mathrm{m}}$ is considered a "point of no return" in the apoptosis pathway [60, 61], these findings indicate that HeLa cells subjected to hyperosmotic stress were more sensitive to apoptosis when PC2 was downregulated (Figure 4C). Collectively, these results support previous findings suggesting that PC2 is required for hyperosmotic stress-induced autophagy.

\section{PC2 is required for hyperosmotic stress-induced downregulation of the mTOR pathway}

Our previous data show that the mTOR pathway is modulated by hyperosmotic stress (Figures 2A-2D). Because mTOR, as previously mentioned, is a classic autophagic regulator, we evaluated whether PC2 affects the mTOR pathway under hyperosmotic stress conditions. To this end, we treated HeLa cells with sorbitol or mannitol ( 50 or $200 \mathrm{mOsm}$ ) for $30 \mathrm{~min}$ in the presence of PC2 or after siRNA-mediated downregulation of PC2. Our results show that the absence of $\mathrm{PC} 2$ prevented a decrease in S6 phosphorylation. This protein is downstream of mTOR, and S6 phosphorylation typically decreases when autophagy is induced [23]. Therefore, PC2 may be required for hyperosmotic-stress-induced mTOR pathway downregulation (Figures 5A-5D). Similar results were found in HCT116 cells, suggesting this mechanism occurs in different cell types (Figures 5E-5F). These data indicate that PC2 may regulate hyperosmotic stress-induced autophagy by modulating the mTOR pathway.
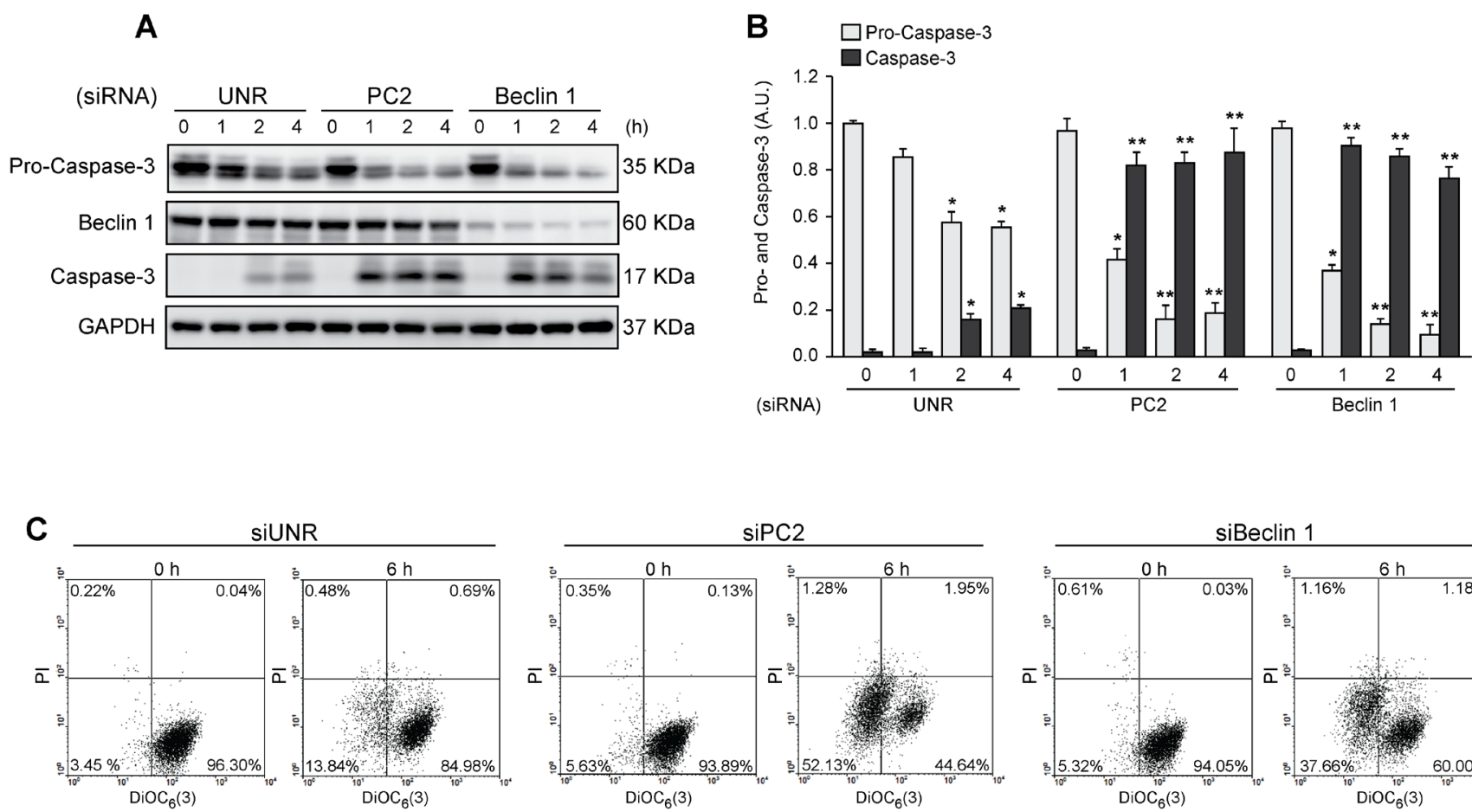

siPC2

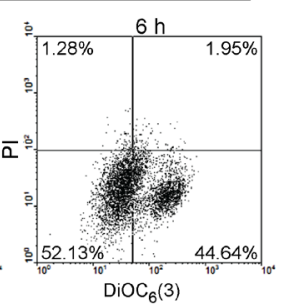

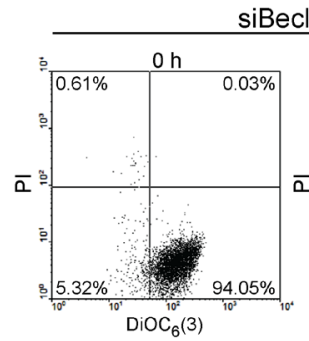

siBeclin 1

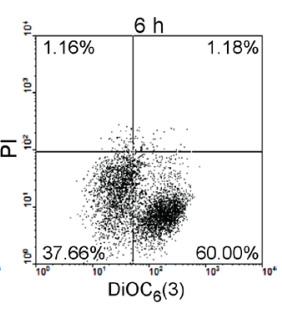

Figure 4: Pro-survival role of autophagy in cells subjected to hyperosmotic stress. HeLa cells were transfected with an unrelated control siRNA (siUNR) or specific siRNAs against PC2 and Beclin $1.48 \mathrm{~h}$ later, cells were exposed to sorbitol (200 mOsm) at the indicated times. Pro-caspase-3, Beclin 1 and caspase-3 levels were evaluated by Western blot analysis. GAPDH levels were used as a loading control. Representative gels are shown in A. Quantification of gel bands is shown in B. (mean \pm SEM, $n=3, * p<0.05 v s .0 \mathrm{~h}$ siUNR, $* * p<0.01 v s .0 \mathrm{~h}$ siUNR). Alternatively, cells were submitted to cytofluorimetric analysis of mitochondrial membrane potential (DiOC 6 (3) staining) and viability (PI staining). C. Representative dot plots of HeLa cells treated for $6 \mathrm{~h}$ with $200 \mathrm{mM}$ sorbitol are shown $(n=3)$. 
A

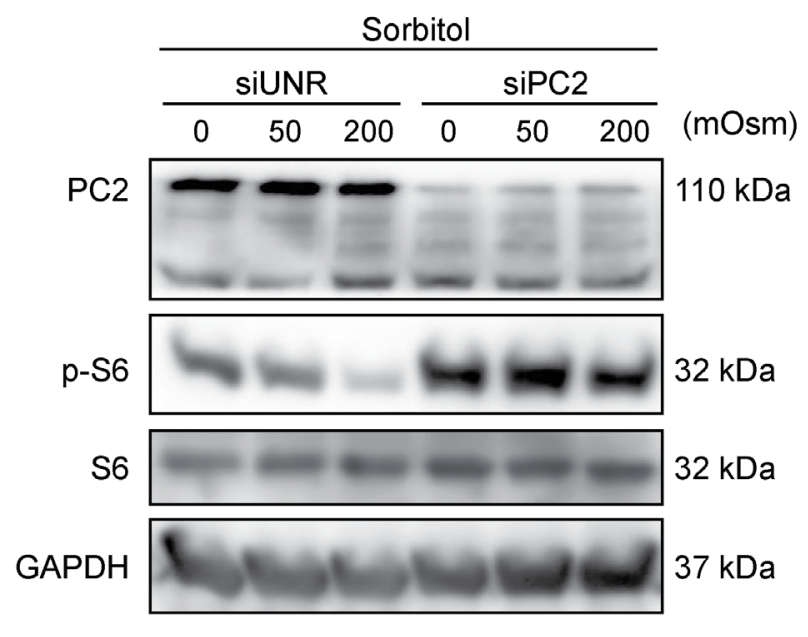

C

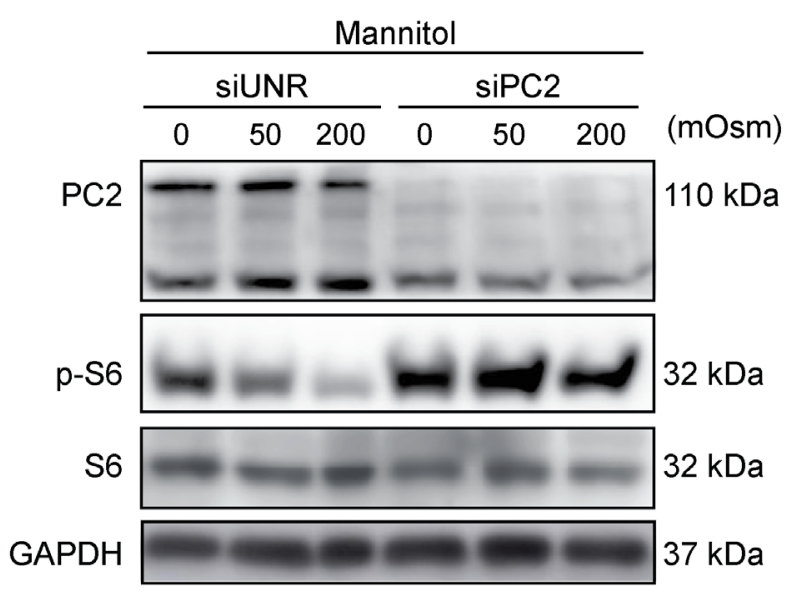

E

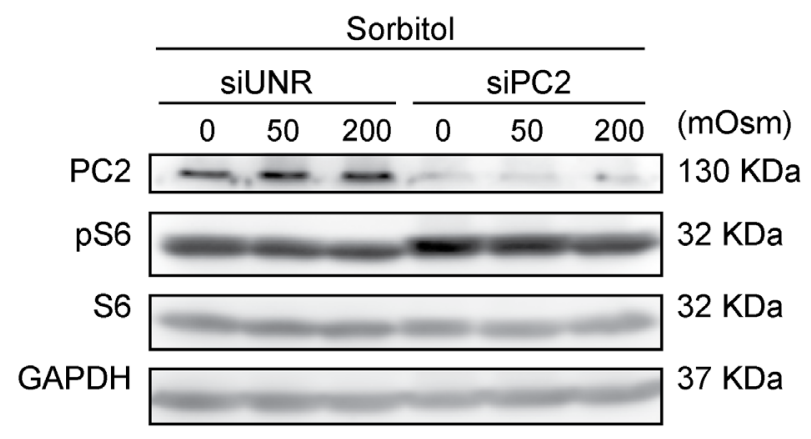

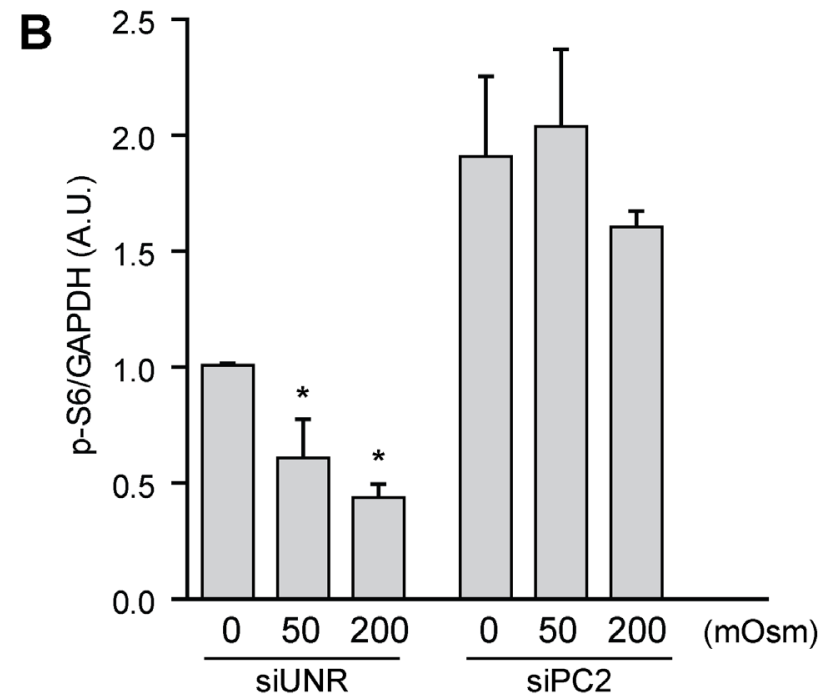
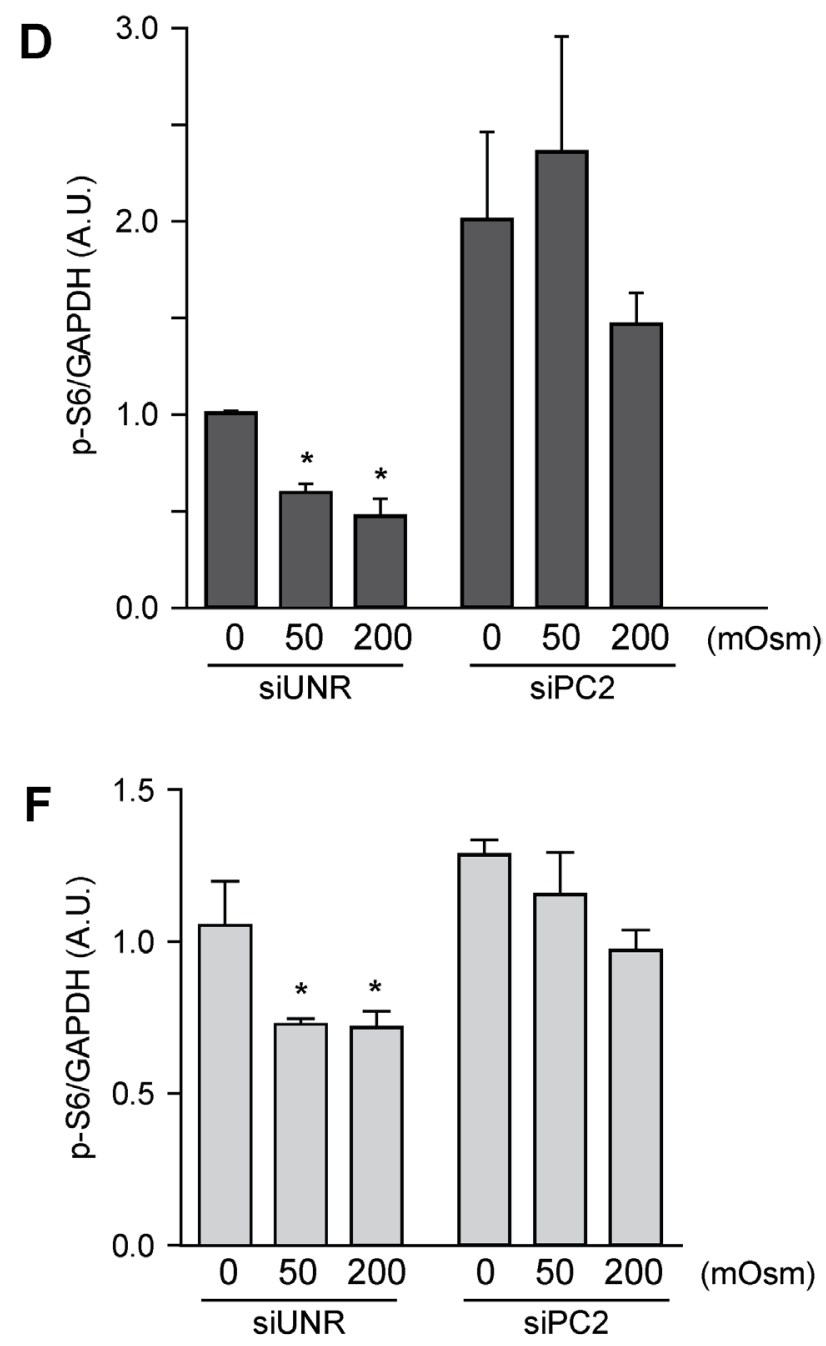

Figure 5: PC2 modulates the mTOR pathway under hyperosmotic stress conditions. PC2 was downregulated in HeLa A.-D. and HCT116 E.-F. cells using a specific siRNA against PC2. An unrelated siRNA (UNR) was used as a control. Subsequently, cells were treated with 0, 50 or 200 mOsm sorbitol or mannitol and p-S6, S6 and PC2 levels were evaluated by Western blot analysis. Representative gels are shown in A., C. and E.. Quantification of gel bands is shown in B., D. and F. (mean $\pm \mathrm{SEM}, n=3,{ }^{*} p<0.05 v s .0 \mathrm{mOsm}$ siUNR). GAPDH levels were used as a loading control. 


\section{DISCUSSION}

Tissues in our body are constantly exposed to systemic and local osmotic alterations [62]. Severe osmotic changes in extracellular fluids are observed under both physiological and pathological conditions. Various mechanisms serve to maintain osmotic homeostasis in cells. While epithelial cells in the renal tubules or duodenal cells in the intestinal tract are routinely subject to severe osmotic variations under physiological conditions [56, 63], other cell types cannot cope with the osmotic variations that characterize some pathologies [64]. Unbalanced osmolarity is associated with disorders such as obesity [4], eye diseases [1], bowel diseases [6], cardiovascular disorders [65, 66], liver diseases [67] and cystic fibrosis [68, 69], among others [64]. In vitro experiments have demonstrated that hyperosmotic conditions stimulate rapid osmoadaptive responses in cells, including synthesis and transport of osmolytes, upregulation of antioxidant pathways and stimulation of mechanisms that promote cell volume recovery [70]. Importantly, we and others demonstrated that a failure of the osmoprotective mechanisms under hyperosmotic stress conditions leads apoptosis [66, 71-73].

Autophagy, along with the unfolded protein response and the ubiquitin-mediated protein degradation pathway, is a cellular mechanism involved in protein homeostasis $[17,18,74]$. Studies have shown that hyperosmotic stress induces autophagy [25-27]. For example, exposing cells to a hyperosmolar solution of $\mathrm{NaCl}$ induces autophagy in Chinese hamster ovary (rCHO) [26], porcine renal proximal tubule-like LLC-PK1 [27] and rat notochordal cells [25]. Despite these findings, there was no evidence available to date to confirm whether hyperosmotic stress induces autophagy in human cells. In the present study, we exposed human cells to sorbitol and mannitol, which belong to the carbohydrate osmolyte polyol family [10]. In mammals, sorbitol is the most predominant osmoprotective carbohydrate compound. Mannitol, which is considered chemically to be a sorbitol isomer, is widely used to modify tonicity in biological fluids [10]. Several studies have used $\mathrm{NaCl}$ to study cellular osmoadaptive mechanisms in vitro. However, $\mathrm{NaCl}$ also activates and increases $\mathrm{Na}^{+} / \mathrm{K}^{+}$-ATPase expression, whereas mannitol does not have this effect [75]. Therefore, we used osmolytes whose effects are limited to their osmotic capacity and do not affect ionic conductivity or transport across the membrane [76, 77].

This study shows that hyperosmotic stress stimulates autophagy in human cell lines (HeLa and HCT116), as indicated by relocalization of LC3 in autophagy vacuoles, LC3 I-to-LC3 II conversion and p62/SQSTM1 degradation (Figure 1). Additionally, specific knockdown of essential autophagy genes such as Beclin 1, ATG7 and VPS34 blunted hyperosmotic stress-induced autophagy (Figure 1). Autophagy flux experiments using HeLa cells in the presence and absence of BafA1 were also consistent with the previous results, demonstrating that both sorbitol and mannitol increased autophagic flux (Figure 1).

While AMPK induces autophagy by phosphorylating the positive regulator of autophagy unc-51-like kinase 1 protein (ULK1) on Ser317 and Ser77 [78], mTOR suppresses autophagy by phosphorylating on Ser757, Ser758 and Ser638 [79]. However, the classical AMPKand mTOR-dependent autophagy does not always occur $[23,80]$. Our results show that the AMPK and mTOR pathways were up- or downregulated, respectively, when HeLa and HCT116 cells were treated with sorbitol or mannitol, revealing that classical regulatory mechanisms are involved in modulating autophagy under hyperosmotic stress conditions (Figure 2).

PC2 is a mechanosensor required for activation of pro-survival cell signals, especially in renal tubules where cells are subject to physiological fluid flow [33]. A recent study showed that fluid shear stress induces autophagy in vitro, mediated by the primary cilium and ciliary PC2 through an mTOR-dependent mechanism [39]. Consistently, we found here that PC2 was required for hyperosmotic stress induced-autophagy in $\mathrm{HeLa}$ and HCT116 cells as evaluated by relocalization of GFP-LC3 in autophagy vacuoles and LC3 I-to-LC3 II conversion (Figure 3). Additionally, our data showed that downregulation of PC2 or Beclin 1 not only inhibited autophagy, but also enhanced levels of the effector short caspase-3, consistent with increased $\Delta \Psi_{\mathrm{m}}$ dissipation (Figure 4). This finding suggests that $\mathrm{PC} 2$-mediated autophagy is an adaptive mechanism that prevents cell death under hyperosmotic stress conditions.

Given that our results showed that the mTOR pathway was inhibited under hyperosmotic stress conditions and that PC2 is required for hyperosmotic stress-induced autophagy, we evaluated whether PC2 is implicated in mTOR inhibition under hyperosmotic conditions. Our findings showed that downregulation of PC2 prevents the mTOR pathway inhibition induced by hyperosmotic stress (Figure 5). These data suggest that PC2 is required to induce autophagy via the mTOR pathway. Collectively, these data provide new insights into the role of PC2 in regulating autophagy in human cells under conditions of hyperosmotic stress.

\section{MATERIALS AND METHODS}

\section{Cell culture and treatment}

Human cervical cancer cell line (HeLa) cells from ATCC were grown in DMEM (glucose, $4.5 \mathrm{~g} / \mathrm{L}$ ) containing L-glutamine and $110 \mathrm{mg} / \mathrm{L}$ sodium pyruvate, supplemented with 10\% FBS and $10 \mathrm{mM}$ HEPES buffer. Human colon cancer cell line (HCT116) cells were 
maintained in McCoy's 5A medium (glucose $4.5 \mathrm{~g} / \mathrm{L}$ ) supplemented with 10\% FBS and 10 mM HEPES buffer. All media, supplements and reagents for cell culture were purchased from Gibco, Invitrogen (Carlsbad, CA, USA). Cells were treated with D-sorbitol or D-mannitol (Sigma-Aldrich Corporation, St. Louis, MO, USA) at concentrations from 0 to $300 \mathrm{mOsm}$ in the presence or absence of Bafilomycin-A1 $(50 \mathrm{nM})$, for the times indicated in the various experiments. All experiments were independently repeated at least three times.

\section{siRNA transfection and adenovirus infection}

siRNAs were purchased from the Sigma-Aldrich Corporation. An unrelated siRNA sequence was used as a negative control. Lipofectamine RNAiMax (Invitrogen) and Opti-MEM culture medium were used for siRNA transfection. $36 \mathrm{~h}$ after transfection, cells were stimulated, and the target protein was measured to evaluate the efficiency of the various siRNAs. For adenovirusmediated protein overexpression, cells were incubated for $12 \mathrm{~h}$ with the AdGFP-LC3 adenovirus, followed by siRNA transfection and/or treatment with mannitol or sorbitol for the indicated times.

\section{Western blot analysis}

Protein samples from HeLa or HCT116 cells were prepared in M-PER lysis buffer (Thermo Scientific) supplemented with protease and phosphatase inhibitors (ROCHE). Aliquots of the extracted proteins (approximately $30 \mu \mathrm{g} /$ lane) were resolved on $12 \% \mathrm{SDS}$ PAGE gel (Bio-Rad) and then subjected to immunoblotting using antibodies specific for ACC (mouse monoclonal IgG clone D-5, cat\# SC-11427, Santa Cruz Biotechnology), p-ACC Ser79 (rabbit polyclonal IgG clone D7D11, cat\# 11818, Cell Signaling Technology), AMPK (mouse monoclonal IgG, cat\# 2793, Cell Signaling Technology), p-AMPK (rabbit polyclonal IgG, cat\# 2531, Cell Signaling Technology), ATG7 (rabbit polyclonal IgG clone D12B11, cat\# 8558, Cell Signaling Technology), Beclin 1 (rabbit polyclonal IgG clone H-300, cat\# SC-11427, Santa Cruz Biotechnology), pro-caspase-3 and caspase-3 (rabbit polyclonal IgG, cat\# 9665, Cell Signaling Technology), GAPDH (mouse monoclonal IgG, cat\# MAB274, Chemicon International), 4EBP1 (rabbit polyclonal IgG, cat\# 9452, Cell Signaling Technology), p-4EBP1 Thr37/46 (rabbit polyclonal IgG clone 236B4, cat\# 2855, Cell Signaling Technology), LC3 I and II (rabbit polyclonal IgG, cat\# 9748, Cell Signaling Technology), p62/SQSTM1 (rabbit polyclonal IgG, cat\# NBP1-42822, Novus Biologicals), PC2 (rabbit polyclonal IgG clone H-280, cat\# sc-25749, Santa Cruz Biotechnology), PI3K-III/ VPS34 (rabbit polyclonal IgG, cat\# 3811, Cell Signaling Technology), S6 (mouse monoclonal IgG clone 54D2, cat\# 2317, Cell Signaling Technology), p-S6 Ser235/236 (rabbit polyclonal IgG clone 236B4, cat\# 2211, Cell Signaling Technology), mTOR (mouse monoclonal IgG clone L27D4, cat\# 4517, Cell Signaling Technology), p-mTOR Ser2481 (rabbit polyclonal IgG, cat\#, Cell Signaling Technology) and $\alpha$-tubulin (mouse monoclonal IgG clone DMA, cat\# T9026, Sigma-Aldrich). Membranes were then incubated with secondary goat anti-mouse or anti-rabbit IgG conjugated to horseradish peroxidase (SouthernBiotech, Birmingham, AL, USA) prior to revelation using the ECL Detection Kit (Amersham Pharmacia, Pittsburgh, PA, USA). Gels were visualized and quantified with ImageJ software (http://rsb.info.nih. gov/ij/).

\section{Confocal and fluorescence microscopy}

Following treatment, cells were washed twice with ice-cold PBS, fixed in paraformaldehyde (4\% w/v) for $15 \mathrm{~min}$, permeabilized with Triton $0.1 \%$, PBS for $10 \mathrm{~min}$ and blocked in 3\% BSA-PBS for $1 \mathrm{~h}$. Nuclei were counterstained with Hoechst 33342 (10 mg/ $\mathrm{mL}$ ) (Molecular Probes). Fluorescence and confocal fluorescence images were captured using an IRE2 microscope equipped with a DC300F camera (both from Leica Microsystems GmbH, Wetzlar, Germany) and an LSM 510 microscope (Carl Zeiss, Jena, Germany). Images were analyzed with ImageJ software (http://rsb.info.nih. gov/ij/).

\section{Cytofluorometry}

The following fluorochromes were used to assess for apoptosis-associated changes: 3,3'-dihexyloxacarbocyanine iodide $\left(\mathrm{DiOC}_{6}(3), 40\right.$ $\mathrm{nM}$, Molecular Probes, Invitrogen), for quantification of mitochondrial transmembrane potential $\left(\Delta \Psi_{\mathrm{m}}\right)$, and propidium iodide (PI, $1 \mu \mathrm{g} / \mathrm{ml}$, Molecular Probes, Invitrogen), to determine cell viability [31]. After trypsinization, cells were stained with $\mathrm{DiOC}_{6}(3)$ for 30 min at $37^{\circ} \mathrm{C}$. Cells were then stained with PI for 5 min at $37^{\circ} \mathrm{C}$, followed by cytofluorometric analysis with FACS Vantage equipment (Becton Dickinson, San Jose, CA, USA).

\section{RNA isolation and RT-qPCR assay}

Total RNA was isolated from HeLa cells using Trizol reagent. A total of 100-250 ng RNA was used for reverse transcription with the iScript kit (Bio-Rad). The reverse transcription product was then diluted 10-fold with ddH2O. $2 \mathrm{~mL}$ of DNA was used for quantitative PCR analysis (StepOnePlus Real-Time PCR System). The forward and reverse primers for 
MAP1LC3B were CCGTCGGAGAAGACCTTCAA and GCATAGACCATGTACAGGAA, respectively. $G A P D H$ was evaluated as a housekeeping gene. The forward and reverse primers were TCAACGACCACTTTGTCAAGCTCA and GCTGGTGGTCCAGGGGTCTTACT, respectively.

\section{Results and statistical analysis}

Results are shown as the mean \pm SEM from at least three independent experiments. Statistical analyses were performed using one-way ANOVA (GraphPad Software, Inc.). $p<0.05$ was considered to be statistically significant.

\section{Abbreviations}

Acetyl-CoA carboxylase (ACC), AMP-dependent kinase (AMPK), A.U. (arbitrary units), Bafilomycin A1 (BafA1), Chinese hamster ovary (CHO), class III phosphatidylinositol 3-kinase complex (PI3KC3), human cervical cancer (HeLa) cells, human colon tumor (HCT116) cells, mechanistic target of rapamycin (mTOR), nuclear factor kappa beta (NF-kB), polycystin-2 (PC2), polycystic kidney disease (PKD), p38 mitogen-activated protein kinase (p38 MAPK), vacuolar protein sorting 34 (VPS34), 4E-binding protein 1 (4EBP1), uncoordinated 51-like kinase 1 protein (ULK1).

\section{ACKNOWLEDGMENTS}

We sincerely thank the members of the Criollo and Lavandero laboratories for discussion and constructive criticism. We are grateful to our sponsors. This research was supported by Fondo Nacional de Desarrollo Cientifico y Tecnologico (FONDECYT) grants 11130285 to R.T., 1161123 to M.B., 1160820 to E.M., and 1140908 to A.C.; by FONDAP grant 15130011 to R.T., S.L. and A.C.; by a CONICYT PhD fellowship program support to D.P-O.; by the PEW Latin American Fellows Program in the Biomedical Sciences grant 00002991 to A.C.; and by the International Centre for Genetic Engineering and Biotechnology (ICGEB) grant CRP/CH113-04RG to M.B. and CRP/CHL16-06 to E.M

\section{CONFLICTS OF INTEREST}

The authors declare that no competing interests exist.

\section{FUNDING}

Fondo Nacional de Desarrollo Cientifico y Tecnológico (FONDECYT) grants 11130285 to R.T.,
1161123 to M.B., 1160820 to E.M. and 1140908 to A.C. Fondo de Financiamiento de Centros de Investigación en Áreas Prioritarias (FONDAP) grants 15130011 to R.T., S.L. and A.C. Comisión Nacional de Investigación Científica y Tecnológica (CONICYT) PhD fellowship program support to D.P-O. PEW Latin American Fellows Program in the Biomedical Sciences grant 00002991 to A.C. International Centre for Genetic Engineering and Biotechnology (ICGEB) grant CRP/CH113-04RG to M.B. and CRP/CHL16-06 to E.M.

\section{REFERENCES}

1. Lemp MA, Bron AJ, Baudouin C, Benitez Del Castillo JM, Geffen D, Tauber J, Foulks GN, Pepose JS, Sullivan BD. Tear osmolarity in the diagnosis and management of dry eye disease. Am J Ophthalmol. 2011; 151:792-8 e1.

2. Pan Z, Wang Z, Yang H, Zhang F, Reinach PS. TRPV1 activation is required for hypertonicity-stimulated inflammatory cytokine release in human corneal epithelial cells. Invest Ophthalmol Vis Sci. 2011; 52:485-493.

3. Stookey JD. High prevalence of plasma hypertonicity among community-dwelling older adults: results from NHANES III. J Am Diet Assoc. 2005; 105:1231-1239.

4. Stookey JD, Barclay D, Arieff A, Popkin BM. The altered fluid distribution in obesity may reflect plasma hypertonicity. Eur J Clin Nutr. 2007; 61:190-199.

5. Berga-Bolanos R, Drews-Elger K, Aramburu J, LopezRodriguez C. NFAT5 regulates T lymphocyte homeostasis and CD24-dependent $\mathrm{T}$ cell expansion under pathologic hypernatremia. J Immunol. 2010; 185:6624-6635.

6. Vernia P, Gnaedinger A, Hauck W, Breuer RI. Organic anions and the diarrhea of inflammatory bowel disease. Dig Dis Sci. 1988; 33:1353-1358.

7. Schilli R, Breuer RI, Klein F, Dunn K, Gnaedinger A, Bernstein J, Paige M, Kaufman M. Comparison of the composition of faecal fluid in Crohn's disease and ulcerative colitis. Gut. 1982; 23:326-332.

8. Umenishi F, Yoshihara S, Narikiyo T, Schrier RW. Modulation of hypertonicity-induced aquaporin-1 by sodium chloride, urea, betaine, and heat shock in murine renal medullary cells. J Am Soc Nephrol. 2005; 16:600-607.

9. Lee SD, Choi SY, Lim SW, Lamitina ST, Ho SN, Go WY, Kwon HM. TonEBP stimulates multiple cellular pathways for adaptation to hypertonic stress: organic osmolytedependent and -independent pathways. Am J Physiol Renal Physiol. 2011; 300:F707-F715.

10. Yancey PH. Organic osmolytes as compatible, metabolic and counteracting cytoprotectants in high osmolarity and other stresses. J Exp Biol. 2005; 208:2819-2830.

11. Santos BC, Pullman JM, Chevaile A, Welch WJ, Gullans SR. Chronic hyperosmolarity mediates constitutive expression of molecular chaperones and resistance to injury. Am J Physiol Renal Physiol. 2003; 284:F564-F574. 
12. Ly DL, Waheed F, Lodyga M, Speight P, Masszi A, Nakano H, Hersom M, Pedersen SF, Szaszi K, Kapus A. Hyperosmotic stress regulates the distribution and stability of myocardin-related transcription factor, a key modulator of the cytoskeleton. Am J Physiol Cell Physiol. 2013; 304:C115-C127.

13. Bustamante M, Roger F, Bochaton-Piallat ML, Gabbiani G, Martin PY, Feraille E. Regulatory volume increase is associated with p38 kinase-dependent actin cytoskeleton remodeling in rat kidney MTAL. Am J Physiol Renal Physiol. 2003; 285:F336-F347.

14. Gankam-Kengne F, Couturier BS, Soupart A, Brion JP, Decaux G. Osmotic Stress-Induced Defective Glial Proteostasis Contributes to Brain Demyelination after Hyponatremia Treatment. J Am Soc Nephrol. 2017; 28:1802-1813. doi: 10.1681/ASN.2016050509.

15. Greenwood M, Greenwood MP, Paton JF, Murphy D. Transcription Factor CREB3L1 Regulates Endoplasmic Reticulum Stress Response Genes in the Osmotically Challenged Rat Hypothalamus. PLoS One. 2015; 10:e0124956.

16. Lee SH, Park Y, Yoon SK, Yoon JB. Osmotic stress inhibits proteasome by p38 MAPK-dependent phosphorylation. J Biol Chem. 2010; 285:41280-41289.

17. Kaur J, Debnath J. Autophagy at the crossroads of catabolism and anabolism. Nat Rev Mol Cell Biol. 2015; 16:461-472.

18. Tanaka K, Matsuda N. Proteostasis and neurodegeneration: the roles of proteasomal degradation and autophagy. Biochim Biophys Acta. 2014; 1843:197-204.

19. Suzuki K, Noda T, Ohsumi Y. Interrelationships among Atg proteins during autophagy in Saccharomyces cerevisiae. Yeast. 2004; 21:1057-1065.

20. Bento CF, Renna M, Ghislat G, Puri C, Ashkenazi A, Vicinanza M, Menzies FM, Rubinsztein DC. Mammalian Autophagy: How Does It Work? Annu Rev Biochem. 2016; 85:685-713.

21. Mizushima N, Yoshimori T, Ohsumi Y. The role of Atg proteins in autophagosome formation. Annu Rev Cell Dev Biol. 2011; 27:107-132.

22. Suzuki K, Kubota Y, Sekito T, Ohsumi Y. Hierarchy of Atg proteins in pre-autophagosomal structure organization. Genes Cells. 2007; 12:209-218.

23. Chantranupong L, Sabatini DM. Cell biology: The TORC1 pathway to protein destruction. Nature. 2016; 536: 155-156.

24. Prick T, Thumm M, Kohrer K, Haussinger D, Vom Dahl S. In yeast, loss of Hog1 leads to osmosensitivity of autophagy. Biochem J. 2006; 394:153-161.

25. Jiang LB, Cao L, Yin XF, Yasen M, Yishake M, Dong J, Li XL. Activation of autophagy via $\mathrm{Ca}(2+)$-dependent AMPK/mTOR pathway in rat notochordal cells is a cellular adaptation under hyperosmotic stress. Cell Cycle. 2015; 14:867-879.

26. Han YK, Kim YG, Kim JY, Lee GM. Hyperosmotic stress induces autophagy and apoptosis in recombinant Chinese hamster ovary cell culture. Biotechnol Bioeng. 2010; 105:1187-1192.

27. Nunes P, Ernandez T, Roth I, Qiao X, Strebel D, Bouley R, Charollais A, Ramadori P, Foti M, Meda P, Feraille E, Brown D, Hasler U. Hypertonic stress promotes autophagy and microtubule-dependent autophagosomal clusters. Autophagy. 2013; 9:550-567.

28. Eisner V, Quiroga C, Criollo A, Eltit JM, Chiong M, Parra V, Hidalgo K, Toro B, Diaz-Araya G, Lavandero S. Hyperosmotic stress activates p65/RelB NFkappaB in cultured cardiomyocytes with dichotomic actions on caspase activation and cell death. FEBS Lett. 2006; 580:3469-3476.

29. Comb WC, Hutti JE, Cogswell P, Cantley LC, Baldwin AS. p85alpha SH2 domain phosphorylation by IKK promotes feedback inhibition of PI3K and Akt in response to cellular starvation. Mol Cell. 2012; 45:719-730.

30. Criollo A, Senovilla L, Authier H, Maiuri MC, Morselli E, Vitale I, Kepp O, Tasdemir E, Galluzzi L, Shen S, Tailler M, Delahaye N, Tesniere A, et al. IKK connects autophagy to major stress pathways. Autophagy. 2010; 6:189-191.

31. Criollo A, Galluzzi L, Maiuri MC, Tasdemir E, Lavandero S, Kroemer G. Mitochondrial control of cell death induced by hyperosmotic stress. Apoptosis. 2007; 12:3-18.

32. Delmas P. Polycystins: from mechanosensation to gene regulation. Cell. 2004; 118:145-148.

33. Patel A, Honore E. Polycystins and renovascular mechanosensory transduction. Nat Rev Nephrol. 2010; 6:530-538.

34. Chapin HC, Caplan MJ. The cell biology of polycystic kidney disease. J Cell Biol. 2010; 191:701-710.

35. Shillingford JM, Leamon CP, Vlahov IR, Weimbs T. Folateconjugated rapamycin slows progression of polycystic kidney disease. J Am Soc Nephrol. 2012; 23:1674-1681.

36. Perico N, Antiga L, Caroli A, Ruggenenti P, Fasolini G, Cafaro M, Ondei P, Rubis N, Diadei O, Gherardi G, Prandini S, Panozo A, Bravo RF, et al. Sirolimus therapy to halt the progression of ADPKD. J Am Soc Nephrol. 2010; 21:1031-1040.

37. Spirli C, Okolicsanyi S, Fiorotto R, Fabris L, Cadamuro M, Lecchi S, Tian X, Somlo S, Strazzabosco M. Mammalian target of rapamycin regulates vascular endothelial growth factor-dependent liver cyst growth in polycystin-2-defective mice. Hepatology. 2010; 51:1778-1788.

38. Tao Y, Kim J, Schrier RW, Edelstein CL. Rapamycin markedly slows disease progression in a rat model of polycystic kidney disease. J Am Soc Nephrol. 2005; 16:4651.

39. Orhon I, Dupont N, Zaidan M, Boitez V, Burtin M, Schmitt A, Capiod T, Viau A, Beau I, Kuehn EW, Friedlander G, Terzi F, Codogno P. Primary-cilium-dependent autophagy controls epithelial cell volume in response to fluid flow. Nat Cell Biol. 2016; 18:657-667. 
40. Shillingford JM, Murcia NS, Larson CH, Low SH, Hedgepeth R, Brown N, Flask CA, Novick AC, Goldfarb DA, Kramer-Zucker A, Walz G, Piontek KB, Germino GG, et al. The mTOR pathway is regulated by polycystin-1, and its inhibition reverses renal cystogenesis in polycystic kidney disease. Proc Natl Acad Sci U S A. 2006; 103:54665471.

41. Wahl PR, Serra AL, Le Hir M, Molle KD, Hall MN, Wuthrich RP. Inhibition of mTOR with sirolimus slows disease progression in Han:SPRD rats with autosomal dominant polycystic kidney disease (ADPKD). Nephrol Dial Transplant. 2006; 21:598-604.

42. Boletta A. Emerging evidence of a link between the polycystins and the mTOR pathways. Pathogenetics. 2009; 2:6.

43. Distefano G, Boca M, Rowe I, Wodarczyk C, Ma L, Piontek KB, Germino GG, Pandolfi PP, Boletta A. Polycystin-1 regulates extracellular signal-regulated kinase-dependent phosphorylation of tuberin to control cell size through mTOR and its downstream effectors S6K and 4EBP1. Mol Cell Biol. 2009; 29:2359-2371.

44. Klionsky DJ, Abdelmohsen K, Abe A, Abedin MJ, Abeliovich H, Acevedo Arozena A, Adachi H, Adams CM, Adams PD, Adeli K, Adhihetty PJ, Adler SG, Agam $\mathrm{G}$, et al. Guidelines for the use and interpretation of assays for monitoring autophagy (3rd edition). Autophagy. 2016; $12: 1-222$.

45. Wu L, Feng Z, Cui S, Hou K, Tang L, Zhou J, Cai G, Xie Y, Hong Q, Fu B, Chen X. Rapamycin upregulates autophagy by inhibiting the mTOR-ULK1 pathway, resulting in reduced podocyte injury. PLoS One. 2013; 8:e63799.

46. Nalbandian A, Llewellyn KJ, Nguyen C, Yazdi PG, Kimonis VE. Rapamycin and chloroquine: the in vitro and in vivo effects of autophagy-modifying drugs show promising results in valosin containing protein multisystem proteinopathy. PLoS One. 2015; 10:e122888.

47. Zhong Y, Wang QJ, Li X, Yan Y, Backer JM, Chait BT, Heintz N, Yue Z. Distinct regulation of autophagic activity by $A \operatorname{tg} 14 \mathrm{~L}$ and Rubicon associated with Beclin 1-phosphatidylinositol-3-kinase complex. Nat Cell Biol. 2009; 11:468-476.

48. Komatsu M, Waguri S, Ueno T, Iwata J, Murata S, Tanida I, Ezaki J, Mizushima N, Ohsumi Y, Uchiyama Y, Kominami E, Tanaka K, Chiba T. Impairment of starvation-induced and constitutive autophagy in Atg7-deficient mice. J Cell Biol. 2005; 169:425-434.

49. Kim J, Kim YC, Fang C, Russell RC, Kim JH, Fan W, Liu R, Zhong Q, Guan KL. Differential regulation of distinct Vps34 complexes by AMPK in nutrient stress and autophagy. Cell. 2013; 152:290-303.

50. Kimura S, Noda T, Yoshimori T. Dissection of the autophagosome maturation process by a novel reporter protein, tandem fluorescent-tagged LC3. Autophagy. 2007; $3: 452-460$.
51. Mauvezin C, Neufeld TP. Bafilomycin A1 disrupts autophagic flux by inhibiting both V-ATPase-dependent acidification and Ca-P60A/SERCA-dependent autophagosome-lysosome fusion. Autophagy. 2015; 11:1437-1438.

52. Kim J, Kundu M, Viollet B, Guan KL. AMPK and mTOR regulate autophagy through direct phosphorylation of Ulk1. Nat Cell Biol. 2011; 13:132-141.

53. Mochizuki T, Wu G, Hayashi T, Xenophontos SL, Veldhuisen B, Saris JJ, Reynolds DM, Cai Y, Gabow PA, Pierides A, Kimberling WJ, Breuning MH, Deltas CC, et al. PKD2, a gene for polycystic kidney disease that encodes an integral membrane protein. Science. 1996; 272:1339-1342.

54. Witzgall R. Polycystin-2--an intracellular or plasma membrane channel? Naunyn Schmiedebergs Arch Pharmacol. 2005; 371:342-347.

55. Hoffmeister H, Babinger K, Gurster S, Cedzich A, Meese C, Schadendorf K, Osten L, de Vries U, Rascle A, Witzgall R. Polycystin-2 takes different routes to the somatic and ciliary plasma membrane. J Cell Biol. 2011; 192:631-645.

56. Lanaspa MA, Andres-Hernando A, Li N, Rivard CJ, Cicerchi C, Roncal-Jimenez C, Schrier RW, Berl T. The expression of aquaporin-1 in the medulla of the kidney is dependent on the transcription factor associated with hypertonicity, TonEBP. J Biol Chem. 2010; 285:3169431703.

57. Machnik A, Neuhofer W, Jantsch J, Dahlmann A, Tammela T, Machura K, Park JK, Beck FX, Muller DN, Derer W, Goss J, Ziomber A, Dietsch P, et al. Macrophages regulate salt-dependent volume and blood pressure by a vascular endothelial growth factor-C-dependent buffering mechanism. Nat Med. 2009; 15:545-552.

58. Pietuch A, Bruckner BR, Janshoff A. Membrane tension homeostasis of epithelial cells through surface area regulation in response to osmotic stress. Biochim Biophys Acta. 2013; 1833:712-722.

59. Galluzzi L, Baehrecke EH, Ballabio A, Boya P, BravoSan Pedro JM, Cecconi F, Choi AM, Chu CT, Codogno P, Colombo MI, Cuervo AM, Debnath J, Deretic V, et al. Molecular definitions of autophagy and related processes. EMBO J. 2017; 36:1811-1836.

60. Galluzzi L, Bravo-San Pedro JM, Vitale I, Aaronson SA, Abrams JM, Adam D, Alnemri ES, Altucci L, Andrews D, Annicchiarico-Petruzzelli M, Baehrecke EH, Bazan NG, Bertrand MJ, et al. Essential versus accessory aspects of cell death: recommendations of the NCCD 2015. Cell Death Differ. 2015; 22:58-73.

61. Izzo V, Bravo-San Pedro JM, Sica V, Kroemer G, Galluzzi L. Mitochondrial Permeability Transition: New Findings and Persisting Uncertainties. Trends Cell Biol. 2016; 26:655-667.

62. Adler SM, Verbalis JG. Disorders of body water homeostasis in critical illness. Endocrinol Metab Clin North Am. 2006; 35:873-894. 
63. Houpt TR. Patterns of duodenal osmolality in young pigs fed solid food. Am J Physiol. 1991; 261:R569-R575.

64. Brocker C, Thompson DC, Vasiliou V. The role of hyperosmotic stress in inflammation and disease. Biomol Concepts. 2012; 3:345-364.

65. Toney GM, Stocker SD. Hyperosmotic activation of CNS sympathetic drive: implications for cardiovascular disease. J Physiol. 2010; 588:3375-3384.

66. Galvez AS, Ulloa JA, Chiong M, Criollo A, Eisner V, Barros LF, Lavandero S. Aldose reductase induced by hyperosmotic stress mediates cardiomyocyte apoptosis: differential effects of sorbitol and mannitol. J Biol Chem. $2003 ; 278: 38484-38494$.

67. Stoll B, Gerok W, Lang F, Haussinger D. Liver cell volume and protein synthesis. Biochem J. 1992; 287:217-222.

68. Henderson AG, Ehre C, Button B, Abdullah LH, Cai LH, Leigh MW, DeMaria GC, Matsui H, Donaldson SH, Davis CW, Sheehan JK, Boucher RC, Kesimer M. Cystic fibrosis airway secretions exhibit mucin hyperconcentration and increased osmotic pressure. J Clin Invest. 2014; 124:30473060 .

69. Arniges M, Vazquez E, Fernandez-Fernandez JM, Valverde MA. Swelling-activated Ca2+ entry via TRPV4 channel is defective in cystic fibrosis airway epithelia. J Biol Chem. 2004; 279:54062-54068.

70. Yordy MR, Bowen JW. Na,K-ATPase expression and cell volume during hypertonic stress in human renal cells. Kidney Int. 1993; 43: 940-948.

71. Morales MP, Galvez A, Eltit JM, Ocaranza P, Diaz-Araya G, Lavandero S. IGF-1 regulates apoptosis of cardiac myocyte induced by osmotic-stress. Biochem Biophys Res Commun. 2000; 270:1029-1035.
72. Roth I, Leroy V, Kwon HM, Martin PY, Feraille E, Hasler U. Osmoprotective transcription factor NFAT5/TonEBP modulates nuclear factor-kappaB activity. Mol Biol Cell. 2010; 21: 3459-3474.

73. Kim JA, Kwon MJ, Lee-Kwon W, Choi SY, Sanada S, Kwon HM. Modulation of TonEBP activity by SUMO modification in response to hypertonicity. Front Physiol. 2014; 5:200.

74. Scheper W, Nijholt DA, Hoozemans JJ. The unfolded protein response and proteostasis in Alzheimer disease: preferential activation of autophagy by endoplasmic reticulum stress. Autophagy. 2011; 7:910-911.

75. Capasso JM, Rivard CJ, Enomoto LM, Berl T. Chloride, not sodium, stimulates expression of the gamma subunit of $\mathrm{Na} /$ $\mathrm{K}$-ATPase and activates JNK in response to hypertonicity in mouse IMCD3 cells. Proc Natl Acad Sci U S A. 2003; 100:6428-6433.

76. Wick AN, Drury DR. Action of insulin on the permeability of cells to sorbitol. Am J Physiol. 1951; 166:421-423.

77. Fisher RB, Lindsay DB. The action of insulin on the penetration of sugars into the perfused heart. J Physiol. 1956; 131:526-541.

78. Wong PM, Puente C, Ganley IG, Jiang X. The ULK1 complex: sensing nutrient signals for autophagy activation. Autophagy. 2013; 9:124-137.

79. Meijer AJ, Lorin S, Blommaart EF, Codogno P. Regulation of autophagy by amino acids and MTOR-dependent signal transduction. Amino Acids. 2015; 47:2037-2063.

80. Grotemeier A, Alers S, Pfisterer SG, Paasch F, Daubrawa M, Dieterle A, Viollet B, Wesselborg S, Proikas-Cezanne T, Stork B. AMPK-independent induction of autophagy by cytosolic Ca2+ increase. Cell Signal. 2010; 22:914-925. 